\title{
Thermal perception on lingual and labial skin
}

\author{
BARRY G. GREEN \\ Monell Chemical Senses Center, Philadelphia, Pennsylvania
}

\begin{abstract}
The perception of warmth and cold was measured on six labial and lingual loci plus the fingertip. The results indicate that (1) the responsiveness to warming varies substantially across oral sites; (2) compared to warming, the responsiveness to cooling is more homogeneous across oral locations and somewhat stronger relative to the fingertip; (3) the psychophysical function for warmth on the vermilion lip and the labial mucosa has two limbs that may represent the contributions of two sensory systems to perceptions of warmth; and (4) the psychophysical functions on labial skin tend to be accelerated for warmth and decelerated (compressed) for cold. The differences in responsiveness within and between thermal modalities are considered in terms of probable differences in both neural innervation and the physical properties of the skin. It is hypothesized that the oral contribution to thermoregulation, although arguably minor, may be greater for cold than for warmth.
\end{abstract}

The capacity of humans to perceive temperature and temperature change in the mouth is poorly understood. Probably because of its association with the sense of taste, the mouth is often overlooked as a sensor of the nonchemical attributes of ingesta. Yet, because the mouth acts as a valve at the entrance to the alimentary canal, it is reasonable to assume that it should be equipped sensorially to protect the gut from thermal insult and to participate in the regulation of heat gain and heat loss at the body's core. Although simple experience demonstrates that potential nutrients that burn or freeze the mouth are usually rejected as inedible, almost no objective information exists about the oral response to more moderate temperatures. As a consequence, little is known about either the saliency of oral thermal sensations or their capacity to contribute to thermoregulation.

Neglect of oral thermal perception is also noteworthy in view of the early and persistent interest in the electrophysiology of oral thermal innervation. A study of the lingual nerve in cats produced the first isolation and description of a cold-sensitive nerve fiber (Zotterman, 1936), and as recently as 1973 , Hensel chose to describe the general properties of thermal receptors in terms of the wealth of information acquired about lingual afferents.

Previous psychophysical work on oral thermal perception has been limited to analyses of the distribution and density of temperature-sensitive "spots" in the mouth. The presence of cold spots and warm spots was mapped on the lips and gingiva (Strughold, 1925; Yamada, Maruhashi, \& Miyake, 1952), the soft palate (Schriever \& Strughold, 1926) and the tongue (Hirsch \& Schriever, 1929). The

The author wishes to thank Barbara S. Gelhard and Eli Dweck, both for their assistance in data collection and for their helpful comments throughout the study. Support for this research came in part from a grant from the National Institutes of Health (NS 20577-01).

The author's mailing address is: Monell Chemical Senses Center, 3500 Market Street, Philadephia, PA 19104. major findings of the punctiform studies were that warm spots are less prevalent than cold spots on the mucous membranes, that the distribution of temperature spots was heterogeneous, and that the density of spots was generally lower in the mouth than on external skin. What these results really tell us about oral thermal perception is unclear, however, in part because it can no longer be assumed that a sensitive spot is associated with a single sensory receptor (Kenshalo \& Gallegos, 1967) and because it is difficult to relate the detectability of punctate stimuli (each a millimeter or less in diameter) to the perception of the macroscopic stimuli that produce the majority of oral thermal sensations. It is possible that because the temperature senses exhibit spatial summation (J. C. Stevens \& Marks, 1971, 1979), the observed differences in the density of thermally sensitive spots may have a smaller than expected effect on the perception of larger stimuli.

The present study investigated the perception of temperature change at a total of six lingual and labial loci, plus the fingertip. The stimuli were designed to be small enough in size to reveal potential spatial variations in responsiveness, ${ }^{1}$ yet large enough to enable inferences to be made about the functional importance of the thermal senses in the oral cavity. The study was done in two parts: the first investigated perceived warmth, and the second investigated perceived cold. It was discovered that the perceived intensity of a thermal stimulus often depended upon the locus to which it was applied, and that these spatial differences were larger for warmth than for cold. In addition, some of the psychophysical functions obtained on oral tissue had two limbs rather than the simple power functions normally reported for external skin (e.g., Molinari, Greenspan, \& Kenshalo, 1977; J. C. Stevens, Marks, \& Simonson, 1974; J. C. Stevens \& S. S. Stevens, 1963). The psychophysical function for warmth on two labial loci had markedly shallower slopes over the lower temperature range than over the higher temperature range, and many of the cold functions showed the opposite trend of a steeper 
slope at mild temperatures followed by a shallower slope at colder temperatures. Comparisons between the oral regions and the index finger showed that all of the oral sites tested responded more strongly to temperature change than did the fingertip.

\section{EXPERIMENT 1: WARMING}

The first experiment measured the intensity of sensations of warmth produced by local heating of three oral loci and the distal pad of the first digit (index finger). Selection of the oral areas-the vermilion border of the lower lip, the dorsal tonguetip, and the medial-dorsal tongue-was based on their anteromedial location in the mouth, and hence their presumed importance as thermal sensors of ingested materials. The fingertip was chosen for similar anatomical and functional reasons, being the sensory surface best suited to evaluate the thermal properties of materials prior to ingestion. The central question of functional importance therefore was: Is the oral region a good (and uniform) sensor of increases in temperature relative to the hand? Differences in such biophysical factors as thermal conductivity, epidermal thickness, and skin hydration were expected to combine with differences in both the density and variety of innervation (Dixon, 1962; Halata \& Munger, 1983) to produce differences in thermal responsiveness among the four regions.

\section{Methods}

Subjects. Eight women and seven men were paid to participate. Most of the subjects were recruited on the campus of the University of Pennsylvania. None had had prior experience in making numerical judgments of thermal intensity.

Apparatus. The stimuli were five aluminum rods, each $22 \mathrm{~cm}$ in length with a flat cross-sectional area of $0.64 \mathrm{~cm}^{2}$. Between trials, the rods stood in $150-\mathrm{ml}$ glass beakers filled with deionized water, which in turn sat submerged to within about $1 \mathrm{~cm}$ of their tops in five constant-temperature baths (PolyScience Model 450). (The probes were kept in beakers rather than directly in the water baths for purposes of sterility; the probes were cleaned and the beaker water replaced between subjects.) The temperature of the water in the beakers was monitored with a digital thermocouple thermometer (Bailey BAT-12) and kept within $\pm 0.2^{\circ} \mathrm{C}$ of the target temperatures. Informal testing with the aluminum probes prior to the experiment led to the use of bath temperatures of $38^{\circ}, 40^{\circ}, 42^{\circ}, 44^{\circ}$, and $46^{\circ} \mathrm{C}$ in order to produce thermal sensations ranging from mild warmth to strong, but nonpainful, warmth.

Two calibration procedures were used to determine (1) the temperature of the probes at the moment of skin contact, and (2) the change in skin temperature produced during stimulation. Probe temperature was measured by drilling a hole $0.38 \mathrm{~mm}$ in diameter and $5 \mathrm{~mm}$ deep into the side of one of the aluminum rods approximately $1 \mathrm{~mm}$ below the stimulating surface. A microthermocouple, $0.23 \mathrm{~mm}$ in diameter, was inserted in the hole and sealed in place with a drop of silicone glue. After the temperature of the probe had stabilized at a particular bath temperature, it was removed from the bath, dried quickly with a soft paper towel, and allowed to cool in ambient air for a total of $10 \mathrm{sec}$ (timed with an electronic metronome), the approximate time needed to dry the probe and ready it for stimulation on each experimental trial. The probe temperature was then read from the digital thermometer. After 10 measurements at each nominal temperature, the mean probe temperatures at the end of $10 \mathrm{sec}$ equaled $43.9^{\circ}, 42.1^{\circ}, 40.4^{\circ}, 38.8^{\circ}$, and $36.9^{\circ} \mathrm{C}$ for the $46^{\circ}, 44^{\circ}, 42^{\circ}, 40^{\circ}$, and $38^{\circ} \mathrm{C}$ bath temperatures. The largest proportion of cooling occurred during drying, after which temperatures fell at the rate of only $0.1^{\circ} \mathrm{C} \mathrm{sec}^{-1}$ or less during mere exposure to air $\left(\mathrm{ca} 22^{\circ} \mathrm{C}\right)$.
The change in skin temperature produced by each of the five probe temperatures was measured by monitoring changes in the skin-stimulator interface temperature at each body locus. The same thermocouple (time constant $=0.005 \mathrm{sec}$ ) was used, this time held against the skin for $5 \mathrm{sec}$ prior to stimulus contact, after which it was "sandwiched" between the stimulator and the skin. Stimulator contact was maintained for $3 \mathrm{sec}$ (the duration of stimulation during the experiment), at the end of which the interface temperature was read from the thermometer. The difference between the final stimulated temperature and the temperature of the skin before contact ${ }^{2}$ constituted the estimate of $\Delta T$, the change in skin temperature during stimulation. A minimum of 15 measurements (and as many as 30 ) were made at each probe temperature and each locus. Because resting oral skin temperatures were quite uniform across subjects, most of the interface measurements were carried out on one subject (over 450 estimates). However, extensive tests were made on the tongue of a second subject because of the lability of the lingual measurements during stimulation. The total hydration of the lingual surface, its irregular topography, and its dense vascularization apparently combine to produce variable stimulated temperature readings (plus or minus as much as $1^{\circ}$ ). The lingual temperature data are therefore the means of over 300 measurements on two subjects. Spot checks were made at each of the other loci with the second subject, and agreement was always within the variance of the prior measurements (SDs $\leq 0.5^{\circ} \mathrm{C}$ ). Because the temperature of the fingertip can fluctuate by several degrees throughout the day, temperature measurements were made only when digital skin was at approximately $32^{\circ} \mathrm{C}$, the average fingertip temperature measured previously in this laboratory on 15 subjects.

Procedure. The method of magnitude estimation was used to produce suprathreshold functions for perceived warmth. Subjects were instructed to assign numbers to the sensations of warmth that were in proportion to the relative intensity of the sensations, one to another. Practice in the method was given by having subjects assign numbers to represent distances the experimenter produced by varying the separation between his outstretched hands. The subjects were told to avoid use of inches or feet during this practice, and to avoid use of Fahrenheit of Celcius degrees in the experiment itself. No modulus was given, but the subjects were encouraged to assign a number on the first trial that was "a reasonable description of the strength of the warmth sensation at its peak and a number to which you would feel comfortable comparing subsequent sensations that might be stronger or weaker." The first stimulus was at neither temperature extreme, and the first three trials were omitted from the data analysis.

Two observations per subject were obtained at each stimulus temperature on the medial lower lip (the vermilion lip), the tip of the tongue, the medial-dorsal surface of the tongue approximately $3 \mathrm{~cm}$ proximal to the tip, and the tip of the first digit (index finger) of the right hand. The four loci and the five temperatures were presented in pseudorandom order, with the constraint that no locus or temperature be repeated on consecutive trials. The subjects were told prior to each trial which area would be stimulated next, and were asked to open their mouths about halfway to allow stimulation of the lip, or to extend the tongue as far as possible without discomfort to allow stimulation of its tip or dorsal surface. The stimuli were applied manually with light pressure sufficient to produce full contact of the probe surface with the skin, and were held in place for $3 \mathrm{sec}$ (timed with an audible electronic metronome). The subjects reported their magnitude estimate as soon after removal of the probe as possible and before allowing the warmed area of skin to contact adjacent areas of unstimulated skin (e.g., by putting the lips together or touching the roof of the mouth with the tongue). The intertrial interval was about $30 \mathrm{sec}$.

\section{Results and Discussion}

The psychophysical functions for the four body loci are shown in Figures 1A and 1B. Each data point is the geometric mean of 30 observations. Although nonlinear on linear, logarithmic, exponential, and log-log coordinates, the functions are slightly better described by power functions than by any other form, and so are plotted on log$\log$ coordinates. Figure 1A shows the relationship between 


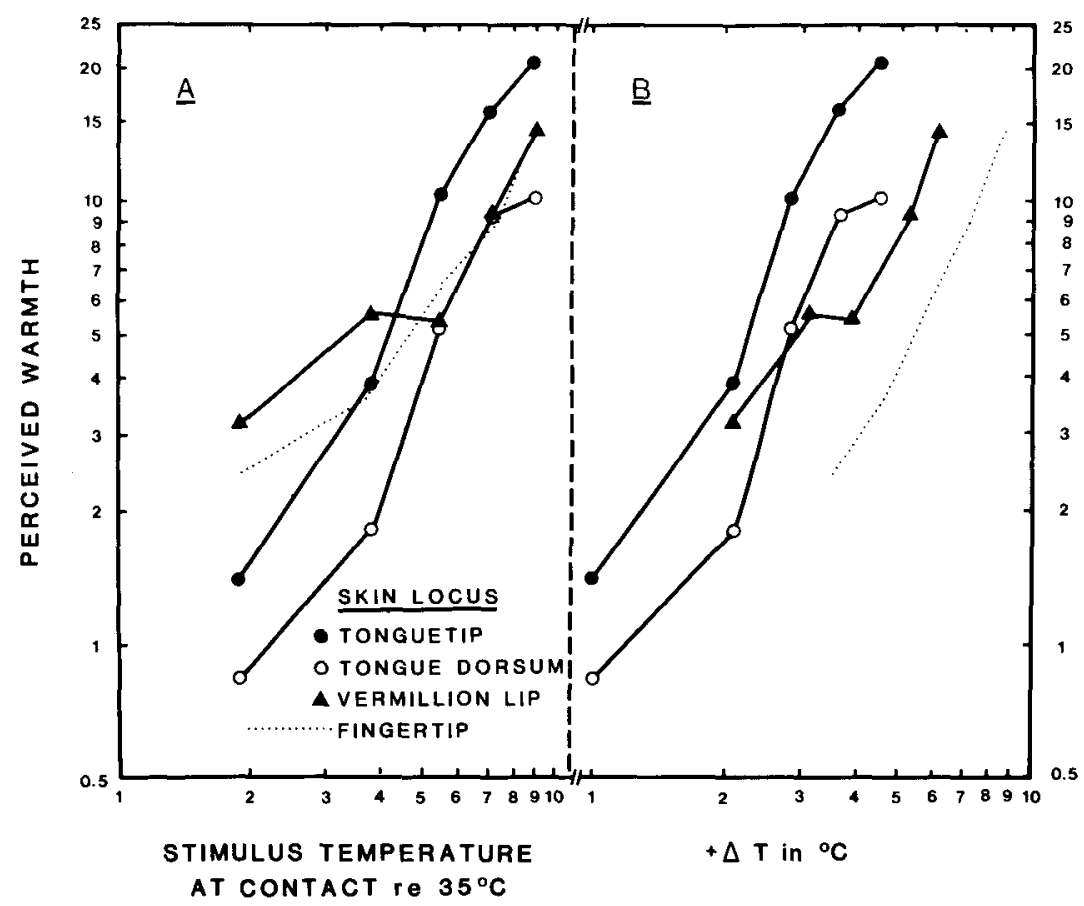

Figure 1. (A) Perceived warmth on three oral loci plus the fingertip as a function of tem-

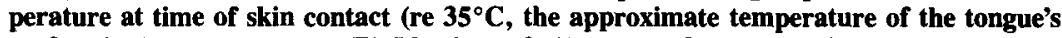
surface in the open mouth). (B) The data of (A) replotted in terms of $+\Delta T$, the increase in skin temperature produced during stimulation.

perceived warmth and stimulus temperature at skin contact, and Figure 1B shows the relationship between perceived warmth and the change $(+\Delta T)$ in skin temperature produced during stimulation. The two depictions of the data address different questions: Figure 1A answers the functional (i.e., behaviorally relevant) question of how intense the perceptual response at each locus will be to a given warm stimulus; Figure $1 \mathrm{~B}$ answers the more physiologic question of how intense the sensory response at each locus will be to a given increment in skin (surface) temperatures. Because the biophysical properties and resting temperatures of the skin vary across body areas, the same stimulus temperature may produce different $\Delta$ Ts at different sites. The $\Delta T$ produced at the various loci by the same stimulus temperature therefore provides information about the thermal conductivity of the different types of skin, which can play a fundamental role in determining the thermal responsiveness at each locus.

Looking first at Figure 1A, the most notable finding is that the three oral areas produce different psychophysical functions. A Friedman two-way ANOVA (subjects $\times$ condition) applied to the oral data revealed a significant effect of oral location on perceived warmth $\left[\chi_{\mathrm{I}}^{2}(2)=13.73\right.$, $\mathrm{p}<.01]$. At the two lowest stimulus temperatures, the vermilion lip appears most responsive to warm stimuli, whereas at higher temperatures, the tonguetip yields the strongest sensations. The dorsal surface of the tongue is consistently less responsive than the tonguetip $\left[\chi_{\mathrm{r}}^{2}(1)=\right.$ $8.07, \mathrm{p}<.01]$, although at high temperatures it equals, or nearly equals, the responsiveness of the lip. The responsiveness of the fingertip is relatively strong at lower temperatures and relatively weak at higher temperatures. The latter result is somewhat surprising in that it would seem advantageous to have distal sensors (i.e., the hands) capable of determining the precise thermal attributes of objects before they reach the mouth. However, most objects brought to the mouth in the hand are grasped by more than a single fingertip, which means that the effective area of the stimulus is considerably larger when the object is grasped than when it is merely poked. Holding an object enables spatial summation to come into play (J.C. Stevens et al., 1974), and the perceived warmth of the object should be substantially greater than that produced under the conditions of this experiment. Nevertheless, Figure 1B demonstrates that when viewed in terms of the actual temperature change at the skin's surface, the fingertip performs much more poorly than any of the oral areas. For example, an increase in surface temperature of $3.5^{\circ} \mathrm{C}$ would be expected to produce sensations of warmth on the tonguetip nearly 6.5 times stronger than on the fingertip. Figure $1 \mathrm{~B}$ also shows that the two lingual functions are nearly parallel, offset by a factor of about 2 to 1 (the tonguetip being twice as responsive as the tongue dorsum). The labial function, which is dominated by a plateau in the midrange of temperatures, demonstrates that the lip is relatively unresponsive to moderate-to-large increases in temperature, less so even than the dorsum of the tongue. More will be said about this result later. 
The heterogeneity of the oral responsiveness to warming is consistent in a qualitative way with the previously described punctiform threshold data (e.g., Hirsch \& Schriever, 1929). However, the virtual absence of warm spots reported for the medial dorsal surface of the tongue is suggestive of a larger difference in lingual responsiveness than the difference obtained here. That the dorsum responds moderately to warming may reflect the presence of spatial summation over the lingual surface (J. C. Stevens et al., 1974); the stimulus probe used in the present experiment is massive as compared to the punctiform stimulators, and may have recruited several spatially distinct warm receptors during each stimulation.

The differences in responsiveness to warming among the oral loci must result from one or more of the following factors: differences in innervation density, differences in receptor type and/or location within the skin, and variables related to the thermal conductivity of the skin. It is known, for example, that the anterior of the oral cavity contains a larger number of nerve endings than the medial and posterior regions (Dixon, 1962), which may contribute to the superior sensitivity of the tonguetip as compared to the tongue dorsum. On the other hand, the parallelism of the lingual functions is reminiscent of what occurs in the auditory system when injury or disease damages the conductive apparatus of the ear and the effective stimulus reaching the basilar membrane is reduced (Thalmann, 1965). In that case, the psychophysical function of the damaged ear has approximately the same slope as that of the normal ear, but a lower $Y$ intercept. In contrast, when hearing loss occurs because of a reduction in the number of receptor cells innervating the basilar membrane, both the slope and the intercept of the auditory functions change. Hence, the lingual data seem more in agreement with differences in thermal conduction than with differences in receptor density. Consistent with the conductivity interpretation is the presence of a thick, keratinized epithelium over the dorsum of the tongue (Jarrett, 1980), which may act as a better thermal insulator than the epithelium of the tonguetip, which borders on the unkeratinized surface of the tongue's ventral side. In addition, Dixon (1962) observed more intraepithelial nerve endings in the anterior of the tongue than elsewhere in the mouth. If, near the tonguetip, the warm receptors lie closer to the surface, the thickness of the epidermis would effectively be reduced and the receptors should respond more readily to increases in surface temperature.

The large differences in the responsiveness to temperature change (Figure 1B) between the oral areas and the fingertip is probably due in part to the differing thermal conductivities of the two kinds of skin. Although the dorsum of the tongue and the fingertip both have a thick epithelium that is a potentially formidable thermal insulator (Lipkin \& Hardy, 1954; Stoll, Chianta, \& Piergallini, 1982; Vendrik \& Vos, 1957), oral skin is probably a better conductor of heat because it is totally hydrated (Lipkin \& Hardy, 1954). The potential enhancement of thermal conduction by hydration became evident during the course of oral temperature measurements, when the stimulated temperature of the vermilion lip was measured either dry or after wetting with the tongue. Stimulus-skin interface temperatures were consistently higher on the moistened lip, probably because the saliva formed an efficient channel for heat flow between the aluminum probe and the irregular surface of the skin. Moisture within the lingual skin should act similarly to shunt heat across the intercellular spaces in the epidermis to the warm receptors below. In contrast, heat probably tends to buildup on the surface of the drier digital corneum, producing relatively large $\Delta \mathrm{Ts}$ while transmitting little heat to receptors. (An analogy can be made to the situation in which a thermal stimulus contacts an excellent thermal insulator-cork for instance-and the interface temperature is observed to rise almost instantly to very near the temperature of the stimulator.) Because of these biophysical factors, it would be unwise to attribute the relatively poor responsiveness of the fingertip to poor thermal innervation.

Besides possible differences in conductivity, the fingertip should also yield weaker sensations of warmth for a particular $\Delta \mathrm{T}$ because of its lower resting (adapted) temperature (ca. $32^{\circ} \mathrm{C}$ compared to ca. $36^{\circ} \mathrm{C}$ on the tongue with the mouth closed). Molinari et al. (1977) demonstrated that perceived warmth was directly related to adapting temperature, which means that if all other factors were equal, for a given $\Delta \mathrm{T}$, the warmer tissue of the mouth should produce stronger sensations of warmth than the finger.

As noted above, the psychophysical function obtained on the vermilion lip was unusual in that it contained a plateau in the midrange of warm temperatures. This result would be unique for a suprathreshold function in most sensory modalities, but has been reported twice before for warm stimulation (Marks \& J. C. Stevens, 1973; Marks, J. C. Stevens, \& Tepper, 1976). The earlier reports of concave-upward warmth functions were, however, limited to radiant stimuli presented to the forehead for durations briefer than those of the present experiment $(\leq 2.0 \mathrm{sec})$; when durations were $3 \mathrm{sec}$ or longer, "normal" power functions were obtained. Marks and Stevens (1973) have hypothesized that two sensory systems are responsible for perception of warmth on the forehead, and that the systems become manifest at brief stimulus durations because the contribution to the sensory response made by one of them is reduced at durations over which temporal summation operates. The present results suggest that the lip is also innervated by at least two warm-sensitive systems, and that one of the systems is less well represented than the other. The plateau in the function may appear over temperatures at which a lower threshold system gives way to a higher threshold system, and is visible because of insufficient overlap between the sensory responses of the two systems. Support for this interpretation comes from electrophysiological data on primates indicating that two populations of receptors respond to warming in the nonnoxious temperature range but have different temperatures of maximum discharge: one at about $40^{\circ} \mathrm{C}$, the other at temperatures in the noxious range of $44^{\circ}-45^{\circ} \mathrm{C}$ (Hensel \& Iggo, 
1971; Konietzny \& Hensel, 1977; Sumino, Dubner, \& Starkman, 1973). The inflection point in the function for the vermilion lip lies near $40^{\circ} \mathrm{C}$, perhaps reflecting a decline in the contribution by the lower intensity system in the absence of a strong contribution by the higher intensity system.

Before such a hypothesis could be entertained further, it was necessary to replicate the labial function; this was accomplished in the next experiment.

\section{EXPERIMENT 2: WARMING}

In addition to a simple replication of the labial measurements, the psychophysical function for warmth was determined on the upper lip as well. This strategy established that the unusual function was a characteristic of the vermilion border in general, not only the lower lip.

\section{Method}

Subjects. A new group of 20 college-age observers ( 10 men and 10 women) were paid to participate.

Apparatus and Procedure. The apparatus and procedures were the same as those of Experiment 1, except that only the upper and lower vermilion lips were stimulated (on the midline).

\section{Results and Discussion}

Figure 2 shows the results of the labial stimulations (geometric means of 40 observations per point). With the larger number of subjects (20 vs. 15 in Experiment 1), The plateau obtained in Experiment 1 became less distinct and, instead, the functions are seen to have two limbs with widely differing slopes. Both labial surfaces showed the same trend: The average slope of the power functions fit-

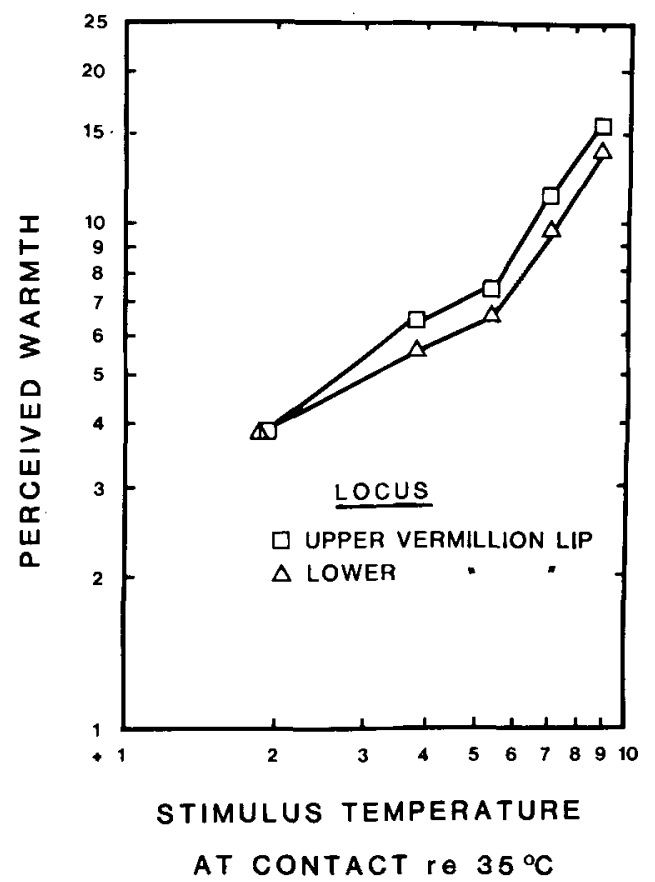

Figure 2. Perceived warmth on the vermilion border of the lips as a function of stimulus temperature at the time of skin contact (re $35^{\circ} \mathrm{C}$ ). ting the two lower limbs was 0.58 , and the slopes of the upper limbs were identical at 1.47 (all rs $>0.98$ ). This means that the perceived warmth of objects that touch the vermilion lips grows about 2.5 times faster at temperatures above $40^{\circ} \mathrm{C}$.

The upper lip yielded significantly larger magnitude estimates than the lower lip (Wilcoxon matched-pairs signedranks test on individual subject means across conditions, $\mathrm{T}=4, \mathrm{p}<.01$ ). The actual difference (an average of $12.5 \%$ ) may, however, be too small to be of functional importance.

When the present data are compared with the data from the other two oral areas of Experiment 1, we see that the slope of the labial functions is inversely related to the "absolute" thermal responsiveness of the lips. That is, the shallower slope obtains over temperatures at which the lip is most responsive when compared to the other loci, which lends support to the notion that if the dual function is due to a reduced innervation of one of two thermal systems, it is probably the higher threshold system that is poorly represented.

\section{EXPERIMENT 3: WARMING}

Along with the possible existence of two subsystems serving warmth, the presence of the two-limb function on the vermilion lip raises questions about the responsiveness of adjacent areas of the lip. In particular, does the dualistic response to warmth mean that the vermilion skin is a transitional zone between the hairy skin of the face, which we might assume is abundantly innervated, and the mucous membranes of the interior of the lip, whose lessexposed surfaces might be more sparsely innervated? This question was answered by measuring the perceptual response to warming on the exterior, medial, and interior surfaces of the lip.

\section{Method \\ Subjects. Another group of 20 college-age subjects (15 females and 5 males) were paid to participate. \\ Apparatus and Procedure. The same psychophysical procedures as before were employed to determine the perceived warmth of stimuli pre- sented to the hairy skin just beneath the vermilion lip, the vermilion lip itself (another replication of the labial data of Experiments 1 and 2), and the mucous membrane inside the lip. The stimuli were the alumi- num probes used in the previous experiments, with their temperatures controlled as before. Measurements of resting skin temperature and $\Delta \mathrm{T}$ on the two new labial areas were also accomplished using the techniques of Experiment 1. \\ The subjects were told at the beginning of each trial which locus would be stimulated next, and they prepared for stimulation by doing one of the following: For the outer lip, the mouth was opened slightly and the lower lip stretched loosely across the lower front teeth by slightly tens- ing the muscles at the corner of the mouth. This provided a flatter sur- face and consequently better contact by the stimulator (all males were clean-shaven). For the vermilion lip, the mouth was simply opened about halfway. For the mucosal skin, the subject rolled the lower lip gently downward using two fingers placed toward the corners of the mouth. In all cases, stimulation was on the midline.}

\section{Results and Discussion}

The geometric means of 40 observations per point are plotted in Figures 3A and 3B. On a few occasions (most 
involving the mucosal lip), subjects felt no sensation of warmth; in those instances, "zeros" were arbitrarily converted to 0.1 for inclusion in the geometric mean.

Two major points can be drawn from the data. First, there is a progressive and substantial loss in responsiveness to warming as the locus of stimulation moves inward from the external lip to the internal lip. Second, the twolimb function consistently observed on the vermilion lip also appears on the mucosal lip.

The dramatic loss in responsiveness over the distance of about $3 \mathrm{~cm}$ constitutes strong circumstantial evidence of significant spatial changes in the density and perhaps the quality of innervation by the warmth sense. When plotted in terms of either stimulus temperature (Figure 3A) or $\Delta \mathrm{T}$ (Figure 3B), the hairy external skin is more responsive to suprathreshold warming than are the other two labial regions, even though, for the reasons described in Experiment 1, the moist mucosal skin is probably a better conductor of heat. A supplemental experiment run on another group of subjects tested the hypothesis that saliva improves heat flow to the skin and consequently increases perceived warmth: When subjects licked their lower lips just prior to stimulation, stimulated skin temperatures rose higher $\left(1.5^{\circ} \mathrm{C}\right.$ on average) and magnitude estimates were significantly larger $(19 \%)$ than on trials when the lip remained dry (Wilcoxon matched-pairs signed-ranks test, $T=36, p<.02)$. Thus, the poor responsiveness of the mucosal lip obtains even though the $+\Delta \mathrm{T}$ at the depth of the receptors is probably large.

When viewed in terms of $\Delta \mathrm{T}$, the difference in the intensity of warm sensations between the external and internal lip ranges from a minimum ratio of about 1.8 to 1 (for
$\Delta \mathrm{T}=2.5^{\circ} \mathrm{C}$ ) to a maximum ratio of twice that, or 3.6 to 1 (for $\Delta \mathrm{T}=6.0^{\circ} \mathrm{C}$ ). As Figures $3 \mathrm{~A}$ and $3 \mathrm{~B}$ show, the difference between the labial regions tends to be greater at the higher skin temperatures, a trend that results from the low slope of the vermilion and mucosal functions over the lower temperatures: Even though the vermilion lip exhabits a responsiveness very near that of the hairy lip for a $\Delta \mathrm{T}$ of $2.2^{\circ} \mathrm{C}$, over the first three $\Delta \mathrm{Ts}$ perceived warmth grows exactly twice as fast on hairy skin as it does on glabrous skin (the slopes of the respective power functions equal 1.24 and 0.62 ). At the three higher temperatures, the functions for both the vermilion lip and the mucosal lip turn upward and obtain slopes similar to the overall slope found for the hairy lip (slopes of 1.50 and 1.26 for the vermilion and mucosal lips, compared to 1.25 for hairy skin).

Differences in resting skin temperature cannot explain the differences in labial responsiveness, primarily because the vermilion lip and hairy lip were identical in temperature $\left(33.5^{\circ} \mathrm{C}\right)$, and the mucosal lip was only $1.5^{\circ} \mathrm{C}$ higher $\left(35.0^{\circ} \mathrm{C}\right)$. This slightly warmer temperature on the inside of the lip does have the effect of producing larger differences between conditions in Figure 3A, yet large differences persist when the data are plotted in terms of $\Delta T$ (Figure 3B). It should also be remembered that for a given $\Delta T$ higher adapting temperatures produce large increments in perceived warmth rather than the smaller increments found on the mucosal lip (Molinari et al., 1977).

It is interesting to speculate on the basis of the present data that (1) other areas of the oral mucosa-particularly the adjacent buccal mucosa-may be as unresponsive to warming as the labial mucosa are, and (2) that the thresh-

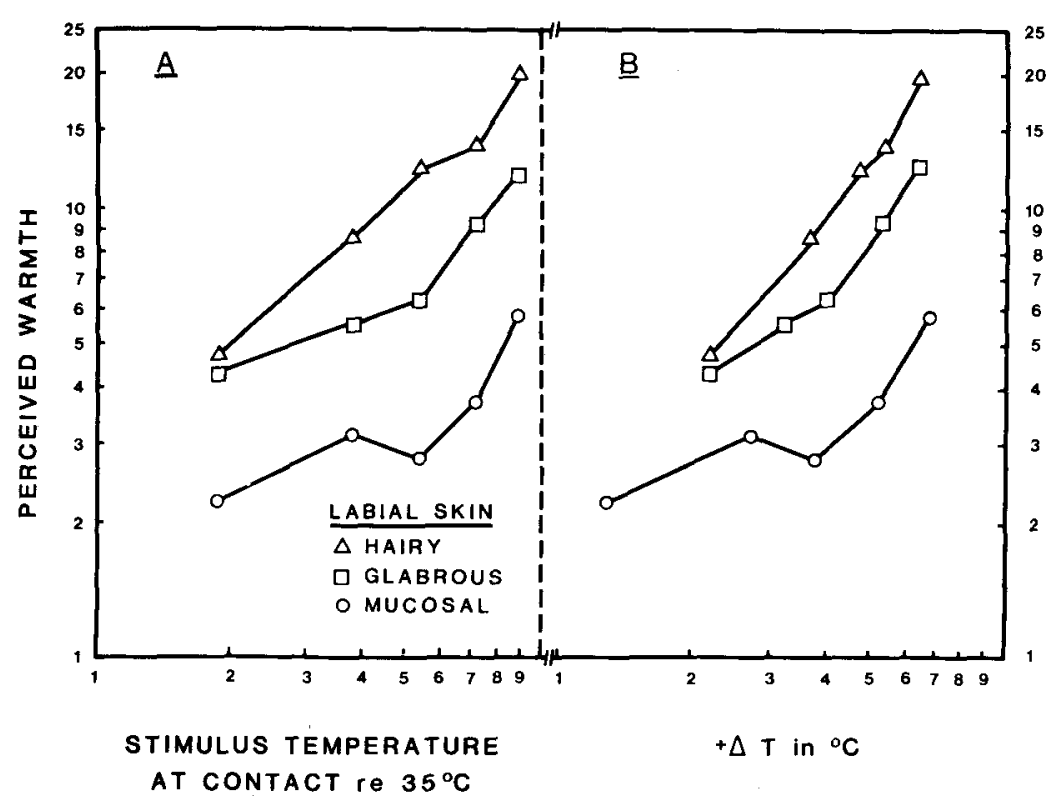

Figure 3. Perceived warmth on three labial loci as a function of (A) stimulus temperature in degrees Centigrade at time of skin contact, and $(B)+\Delta T$, the increase in skin temperature produced during stimulation. ("Glabrous" refers to the skin of the vermilion border.) 
old for heat or heat-pain may be significantly higher on the mucosa than on the hairy skin of the face. The latter point is particularly intriguing because the labial functions show little evidence of convergence at the higher $\Delta \mathrm{Ts}$. Although the final skin temperatures produced on the mucosa by the stimulators reached no higher than $42^{\circ} \mathrm{C}$ and caused no pain, there is evidence (e.g., Beitel \& Dubner, 1976; Handwerker \& Neher, 1976) that heat nociceptors exist in other kinds of skin that begin to become active at about $40^{\circ} \mathrm{C}$ (and may be reflected by the stronger perceived magnitudes obtained near that temperature on the hairy lip). Either the mucosa contains few thermal nociceptors or the nociceptors begin to recruit at higher temperatures and eventually produce extraordinarily steep psychophysical functions. This pattern of results further supports the idea that glabrous and mucosal labial skin is better endowed with warm receptors that respond maximally at lower temperatures than it is with warm receptors that respond maximally at higher temperatures. It should be emphasized, however, that the mucosal lip in particular appears to be poorly innervated by both populations of afferents. Evidence for poor oral innervation by the warmth sense abounds in the sensory physiology literature: The preponderance of thermally responsive afferents in the lingual nerve and the thermally responsive cells in the thalamus respond to cooling but not to warming (Dodt \& Zotterman, 1952; Iriuchijima \& Zotterman, 1960; Nagaki, Yamashita, \& Sato, 1964; Poulos \& Benjamin, 1968; Poulos \& Lende, 1970). The chorda tympani nerve, which is the primary nerve for taste, contains most of the few oral warm fibers reported in nonprimates (Dodt \& Zotterman, 1952; Sato, 1967). Unfortunately, there appear to have been no electrophysiological studies of the thermal components of the mental branch of the mandibular nerve, which innervates the inferior labial mucosa.

\section{EXPERIMENT 4: COOLING}

Experiments 4 and 5 parallel Experiments 1 and 3, using cool instead of warm stimuli.

\section{Method}

Subjects. Fifteen college-age subjects (10 females and 5 males) were paid to participate in the experiment. Most had had no prior experience with a magnitude estimation task.

Apparatus and Procedure. The same temperature control equipment and psychophysical procedures used to measure warmth were used in the present experiment. The stimuli, once again produced with the $0.64-\mathrm{cm}^{2}$ aluminum rods, had nominal temperatures before exposure to air of $28^{\circ}, 24^{\circ}, 20^{\circ}, 16.5^{\circ}$, and $10^{\circ} \mathrm{C}$. These temperatures were selected to produce thermal sensations on the oral tissue ranging from mild cooling to strong (nonpainful) cold. After 10 calibration trials at each temperature during which the rods were dried and exposed to ambient air (ca. $22^{\circ} \mathrm{C}$ ) for $10 \mathrm{sec}$, stimulus temperatures at the time of skin contact were determined to be $27.3^{\circ}, 23.4^{\circ}, 20^{\circ}, 16.4^{\circ}$, and $10.4^{\circ} \mathrm{C}$. (The cold stimuli were less affected by drying and exposure to air than were the warm stimuli because the cold temperatures differed less from ambient temperature.) The changes in skin temperature produced by stimulation were measured as before (see Experiment 1).
Perceived cold was measured two times each on the tonguetip, the tongue dorsum, the lower vermilion lip, and the right index fingertip at each of the five test temperatures. The 15 subjects therefore contributed a total of 30 magnitude estimates per condition.

\section{Results and Discussion}

Figures $4 \mathrm{~A}$ and $4 \mathrm{~B}$ show the relationship between perceived cold and either stimulus temperature $(A)$ or the change in skin temperature, $-\Delta \mathrm{T}(\mathrm{B})$. The following findings are evident: (1) Except at the "warmest" temperature, all oral areas are more responsive to cooling than is the fingertip; (2) unlike what happens for warmth, the tonguetip and the vermilion lip show similarly high responsivity to cooling throughout the range of stimulation; (3) the tongue dorsum is as responsive as the tonguetip until the coldest temperatures are reached; and (4) it matters little whether the data are viewed in terms of initial stimulus temperature or in terms of $-\Delta \mathrm{T}-$ the same relationships hold among loci. Note also that the data are graphed on linear coordinates; the data from the tonguetip and vermilion lip are described well by linear psychophysical functions [tonguetip, (A) $\mathrm{Y}=-1.44 \mathrm{X}+40, \mathrm{r}=$ -0.999 ; (B) $\mathrm{Y}=2.88 \mathrm{X}-9.2, \mathrm{r}=0.988$; lip, (A) $\mathrm{Y}$ $=1.33 \mathrm{X}+38.1, \mathrm{r}=-0.991$; (B) $\mathrm{Y}=2.19 \mathrm{X}-4.1, \mathrm{r}$ $=0.967]$. The dorsum of the tongue, however, seems best described by a function with two linear segments and a breakpoint near $20^{\circ} \mathrm{C}$ (or a $\Delta \mathrm{T}$ of $-6^{\circ} \mathrm{C}$ ).

The superior responsiveness to cooling of the labial and lingual skin when compared to digital skin is more dramatic than the companion results for warmth (Figure 1A), because a cold object below $25^{\circ} \mathrm{C}$ feels less cool on the fingertip than it does on any of the oral structures so far tested. In addition, the slope of the linear function relating perceived cold to $-\Delta \mathrm{T}$ is 3.25 times steeper for the tonguetip than for the fingertip ( 2.89 vs. 0.89). One possible explanation for these differences was that the warmer temperature of the mouth (ca. $33^{\circ}-36^{\circ} \mathrm{C}$ vs. $30^{\circ}-32^{\circ} \mathrm{C}$ ) created the potential for producing larger $-\Delta \mathrm{Ts}$ there than on the finger, and hence concomitantly stronger sensations of cooling. However, Figure $4 \mathrm{~B}$ indicates that $-\Delta \mathrm{Ts}$ at the fingertip are similar to or larger than those obtained on labial and lingual skin. The finger therefore responds less strongly to comparable $-\Delta \mathrm{T}$ s, which implies that the lower adapting temperature is not responsible for the fingertip's poor sensitivity (see Molinari et al., 1977). It is more likely that the thick corneum of the finger, which was earlier implicated in the mediocre sensitivity of the finger to warming, also blunts its responsiveness to cooling. Thus, although the cold stimulus may remove heat from the most superficial layer of the digital epidermis, the corneum apparently slows conductance of heat from the subepithelial layers where the cold receptors reside.

Unlike what was found for the warmth sense, the similarity of the response to cooling for the tonguetip and the vermilion lip implies that objects outside the mouth that are explored first by the tongue will appear equally cool when touched by the lips. The lips and the tongue there- 


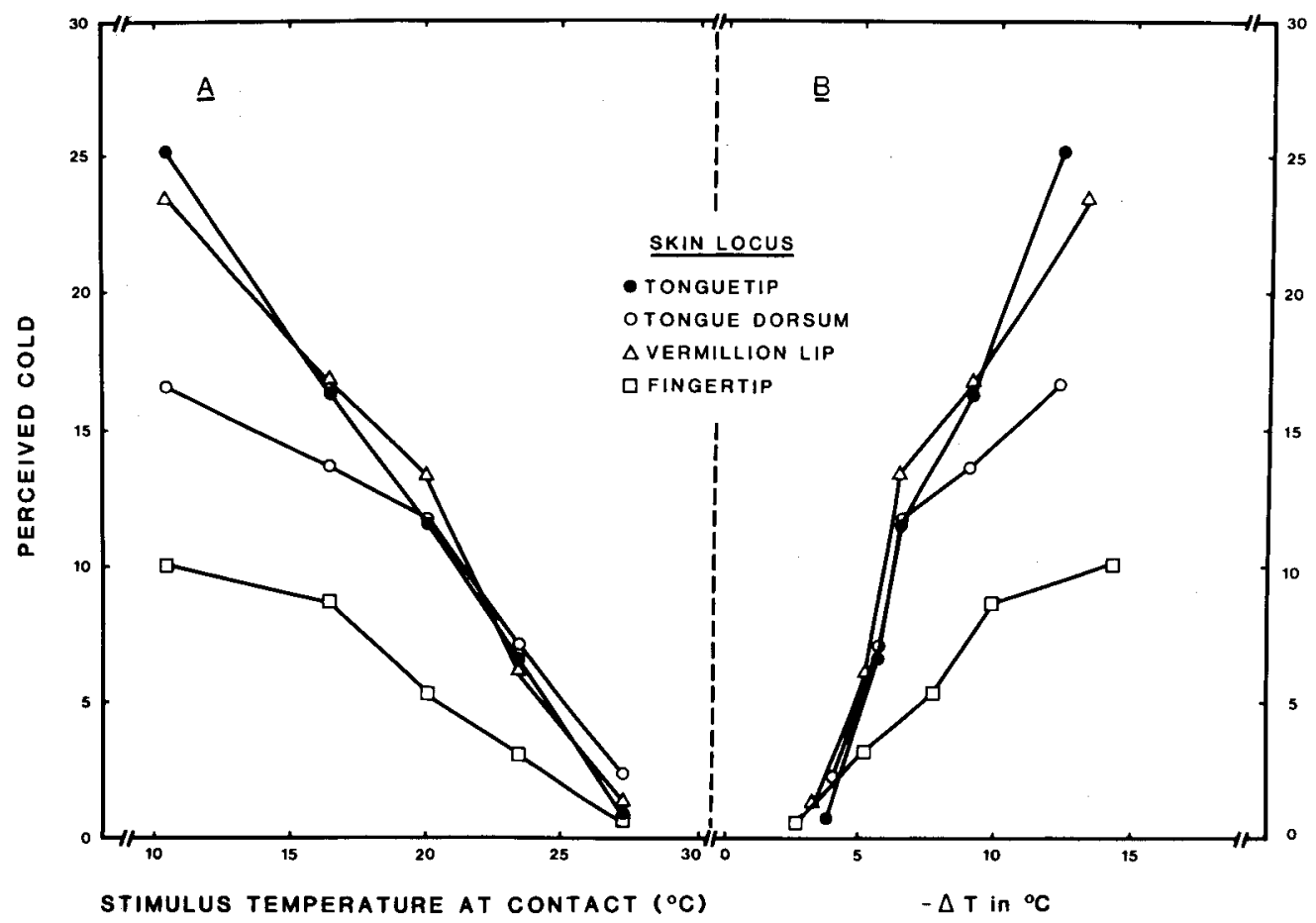

Figure 4. Perceived cold on three oral loci plus the fingertip as a function of (A) stimulus temperature in degrees Centigrade at time of skin contact, and (B) $-\Delta T$, the decrease in skin temperature produced during stimulation.

fore comprise a reasonably uniform system for sensing the coolness of objects prior to ingestion.

Also unlike what happens for warming, mild-tomoderate cooling of the tongue evokes the same response on both the dorsal surface and at the tip; only at the coldest stimulus temperatures $\left(16.5^{\circ}\right.$ and $\left.10^{\circ} \mathrm{C}\right)$ does the tonguetip respond more vigorously than the tongue dorsum. The coincidence of the responses from the two areas at the less cold temperatures suggests that the difference found at more extreme temperatures does not arise from a change in thermal conductivity over the tongue's surface. As pointed out in Experiment 1, a difference in conductivity should produce a difference in $\mathrm{Y}$ intercept (Thalmann, 1965). A more likely hypothesis attributes the decline in slope over the colder temperature region of the dorsal function (from -1.3 over the three higher temperatures to -0.50 over the three lower temperatures) to either a sparser innervation of higher threshold cold receptors (LaMotte \& Thalhammer, 1982) or a deeper lying location of those receptors within the tongue. The attenuated cold-temperature response probably does not by itself constitute evidence of a reduced presence of cold nociceptors on the dorsum (e.g., Bessou \& Perl, 1969; Georgopoulos, 1976), because none of the coldest stimuli were perceived as painful on either the tonguetip or lip, where responsiveness was maximal.

\section{EXPERIMENT 5: COOLING}

Because the sensitivity of the lip to warming varied so dramatically between the regions of hairy skin and mucosal skin on the lip, it was decided to investigate the responsiveness to cooling on the same labial areas.

\section{Method}

Subjects. Twenty college-age subjects (14 women and 6 men) were paid to participate. Three of the 20 had participated in Experiment 4; the remainder had not previously judged cold sensations in the oral cavity.

Apparatus and Procedure. The stimuli were the same as those of Experiment 4, and the stimulation procedure was identical to that of Experiment 3 (labial responsiveness to warming).

\section{Results and Discussion}

The results are shown in Figures 5A and 5B (geometric means of 40 observations per point). In contrast to perception of warmth, the three labial areas produce reasonably similar perceptions of cold when the data are viewed in terms of stimulus temperature (Figure $5 \mathrm{~A}$ ); the labial mucosa are at least as responsive to moderately cool stimuli as the vermilion lip and hairy lip. The tendency toward stronger sensations of cold at temperatures above $20^{\circ} \mathrm{C}$ on the mucosa is not a significant trend; its presence nevertheless dramatizes the difference in responsiveness of the mucosal lip to cold and warm objects.

Figure 5B shows, however, that the apparently strong responsiveness of the mucosal tissue occurs in the presence of relatively large $-\Delta \mathrm{Ts}$. This means that compared to the glabrous skin of the vermilion lip, the mucosa are less responsive to a given decrement in skin temperature. The larger $\Delta \mathrm{Ts}$ obtained on the mucosa are probably due to its higher resting temperature and to its hydration; as discussed above, the presence of moisture should allow rapid heat loss from the epithelium during stimulation. In the 


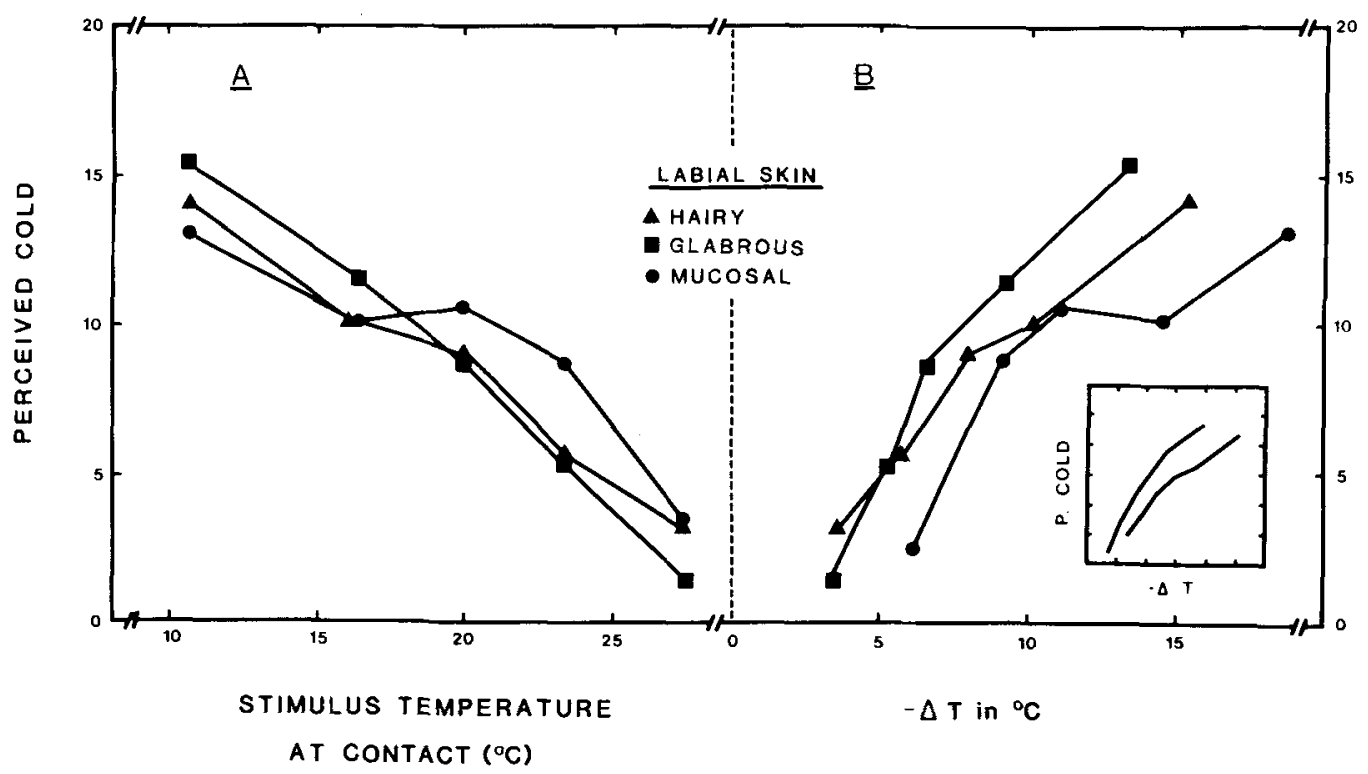

Figure 5. Perceived cold on three labial loci as a function of (A) stimulus temperature in degrees Centigrade at the time of skin contact, and $(B)-\Delta T$, the decrease in skin temperature produced during stimulation. The inset displays data from a secondary experiment on the glabrous skin of the lip (left function) and the mucosal skin of the lip (right function). Each tick mark on the ordinate and abscissa of the inset denotes an increment of 5 units, starting from 0 at the lower left corner.

absence of a keratinized layer, the large $\Delta \mathrm{T}$ s probably reflect substantial temperature changes in the mucosal skin at the depth of the cold receptors. ${ }^{3}$ If so, the smaller perceived magnitudes for a given $\Delta \mathrm{T}$ probably result from the presence of fewer cold receptors in the mucosa than elsewhere in the lip. The end result is that the good functional responsiveness to cold of the inside of the lip probably obtains because the mucosa's higher thermal conductivity compensates for its lower neural density. Test of the validity of this hypothesis awaits electrophysiological survey of the mucosal cold receptor population.

The psychophysical functions in Figure 5B show a strong tendency toward compression (see also J. C. Stevens, 1979). Although the functions might be described as having two linear segments of different slope, the data are suggestive of a logarithmic relationship between $-\Delta T$ and perceived cold. Exact description of the form of the psychophysical function from the present data may be ill-advised, however, because of the relatively high variability of the labial magnitude estimates both within and between subjects. This was particularly true for the mucosal lip, where subjects often reported difficulty in making intensity judgments because of the unusual quality of the cold sensations at that locus. Reports from subjects and our observations indicate that the mucosal sensations are somewhat less distinct both spatially and qualitatively than the sensations of cold on glabrous and hairy skin. Although the mucosal sensations elude precise description, they seem to lack the richness and clarity of normal cold sensations. These qualitative differences caused concern for the reliability of the mucosal results, and prompted a follow-up experiment in which the responsiveness of the vermilion lip and the labial mucosa was tested again on 15 new subjects over a range of nominal stimulus temperatures from $28^{\circ}$ to $0^{\circ} \mathrm{C}$. Displayed as an inset in Figure 5B, the data confirmed the superior responsiveness of the vermilion lip to $-\Delta$ Ts. Also confirmed were the compressed psychophysical functions, which in the follow-up experiment more closely resembled logarithmic functions than they did two-limp linear functions (rs for $\log$ functions $>0.990$ ). The continuing compression of the labial cold functions even at $-\Delta \mathrm{T}$ s of over $25^{\circ} \mathrm{C}$ (in response to the $0^{\circ} \mathrm{C}$ stimulus temperature) constitutes another difference between the labial responses to cooling and warming: more intense heating causes proportionally larger increases in perceived warmth (increasing slope), whereas more intense cooling causes proportionally smaller increases in perceived cold (decreasing slope). Single-unit recordings from cold fibers in the infraorbital nerve in monkeys may, supply a straightforward explanation for these compressed functions: The averaged response from 21 cold fibers showed a marked deceleration for temperature shifts exceeding $6^{\circ} 8^{\circ} \mathrm{C}$ (Dubner, Sumino, $\&$ Wood, 1975). Perhaps this deceleration is visible psychophysically only on regions of skin where, as was hypothesized in Experiment 4 with respect to the dorsum of the tongue, there is a scarcity of high-threshold cold fibers (LaMotte \& Thalhammer, 1982).

\section{GENERAL DISCUSSION}

The present study demonstrates the existence of large differences in thermal responsiveness among labial, lingual, and digital areas of skin. Previously, it was shown that the suprathreshold sensitivity to warmth varies greatly 
over the body's surface (Kenshalo, Decker, \& Hamilton, 1967; J. C. Stevens et al., 1974), yet in no other region has it been reported to change so dramatically over such a short distance as it does in and near the oral cavity. Experiment 3 showed that in the distance of a few centimeters, from external lip to internal lip, the responsiveness to a rise in skin temperature changed by a factor of almost four to one. On external skin, only the face (cheek and forehead) and calf, at near opposite poles of the body, have similarly disparate sensitivities (J. C. Stevens et al., 1974).

Relative to warming, the oral responsiveness to cooling appears both less varied across areas and relatively stronger when compared with perceptions of cooling on the fingertip and the face. The data of Figures $4 \mathrm{~A}$ and $5 \mathrm{~A}$ illustrate that the hairy lip, the vermilion lip, the mucosal lip, and the tonguetip all respond similarly to a cool stimulus. Only the dorsum of the tongue seems to exhibit a below-average responsiveness, and this only to the coldest stimuli. Furthermore, the labial mucosa, which is so unresponsive to warming, exhibits a functional responsiveness to cooling rivaling that of the hairy lip. These inconsistencies across modalities make it impossible to describe thermal perception in the oral cavity in general terms. The mouth appears to be equipped differentially for the assessment of increases versus decreases in temperature, with the sense of cold apparently better developed than the sense of warmth. It may be significant that whereas cold is roughly equally perceived over labial and lingual skin, warmth is perceived well only by areas capable of sensing temperature outside the mouth as well as inside, that is, the vermilion and external lip, and the tonguetip.

As noted at the end of Experiment 5, one instance in which labial skin and the dorsum of the tongue may be construed as less responsive to cooling than to warming is over the range of extreme temperatures, where cold sensations grow less rapidly than do warm sensations. Only the tonguetip produces a clearly linear increase in cold sensation throughout the range of temperatures tested. As was postulated to explain the difference between responsivity of the tonguetip and the tongue dorsum, the highthreshold cold receptors that serve the colder temperatures may be less abundant in some oral areas than they are elsewhere on the body, including the tonguetip. The diminution in the growth of cold sensations in the mouth at the colder temperatures may be of little functional consequence, however, if the teeth become the dominant thermal sensors at colder temperatures. Unpublished data from this laboratory lend support to this hypothesis by showing that when cold water is swished in the mouth, the sensation of cold perceived to arise from the teeth grows as a power function with a slope of $1.6(r=0.998)$, whereas the sensation of cold perceived to arise from the rest of the mouth grows as a power function with a slope of 1.2 $(r=-0.999)$. Another pilot experiment showed that warm water provoked no significant sensation from the teeth until near-painful temperatures were reached.
It is interesting to speculate about why the loci in the interior of the mouth may be more uniformly sensitive to cooling than to warming, and how this difference may reflect the function of the thermal senses in the oral cavity. Perhaps the simplest explanation for the difference in responsiveness is that the temperature of the closed mouth lies near $37^{\circ} \mathrm{C}\left(98^{\circ}-99^{\circ} \mathrm{F}\right)$, a temperature that equals or exceeds the temperature of most environmental liquids and solids. This fact may have had significant impact on the evolution of oral thermal sensitivity: Even in tropical climates where air temperatures routinely reach $37^{\circ} \mathrm{C}$ or above, the temperature of water and hydrated comestibles should remain cooler because of constant cooling by evaporation. Only after humans controlled fire and employed it to heat food-a relatively recent development in evolutionary terms-could there have been frequent exposure of the oral tissues to temperatures significantly above $37^{\circ} \mathrm{C}$. The obverse of this argument is that the higher oral temperature dictates that most ingesta cool the oral tissues, and hence it is likely that a strong and continuous environmental pressure existed for the development of a response to cooling.

Because the primary function of the temperature senses on external skin is to help regulate body temperature, the question arises as to whether or not the oral responsiveness to temperature contributes significantly to thermoregulation. For the reasons just outlined, it is unlikely that oral perceptions of warmth could play an important role in maintaining homeostasis. It seems more likely that ingestion of cool liquids and solids might be relevant to the regulatory process; however, estimates of the heat absorbed in the gut by cool ingesta indicate that oral intake accounts for a very small fraction of the negative heat stress encountered daily. If 2 liters of water were drunk each day (a generous estimate) at a temperature of $10^{\circ} \mathrm{C}\left(50^{\circ} \mathrm{F}\right.$, as it might be in a spring or stream), only 54 calories would be required to raise the water to core temperature. Even a conservative estimate of daily heat production of 2,000 calories (Winslow \& Herrington, 1949) means that the intake of moderate volumes of cold liquids drains only about $3 \%$ of the total heat produced. However, because intake of food and drink tends to be episodic rather than continuous, it may be more appropriate to examine the shortterm consequences of ingesting cold substances. Consider, for example, that to warm only 0.5 liter of $10^{\circ} \mathrm{C}$ water consumed over a period of 30 min would require an amount of heat equal to $45 \%$ of the basal metabolic rate during that period (BMR ca. $60 \mathrm{cal} / \mathrm{h}$, see Nielsen, 1970). While this added demand may pose no immediate threat to survival, it could constitute a substantial short-term metabolic burden in a hypothermic individual whose survival depends upon conservation of metabolic energy long enough to reach warm shelter. Cabanac (1972) has demonstrated that when body core temperature is lower than normal (by as little as $1^{\circ} \mathrm{C}$ ), cold stimulation of the hand is perceived as increasingly unpleasant and warm stimulation as increasingly pleasant. Similarly, Marks and Gonzalez (1974) demonstrated that changes in both ambient temperature 
and skin temperature can alter the pleasantness of thermal stimuli. If oral sensations of cold likewise become unpleasant during exposure to cold and hypothermia, the intake of cold ingesta should be inhibited and the likelihood of transient cold-stress should be reduced. (One need only entertain the thought of consuming ice cream while shivering on a cold winter's day to become convinced of the plausibility of this effect.) On the other hand, oral sensations of coolness might also function to encourage intake of water in hyperthermic individuals, both to supplement the cooling produced by evaporative and radiative heat loss and to replace the water lost to evaporation. Unfortunately, the extent to which oral sensations of coolness may provide motivation for hyperthermic individuals to drink cool liquids seems not to have been studied in humans.

Of the oral areas tested, the tonguetip emerged as the most thermally responsive site overall. This finding correlates well with the excellent tactile acuity of the tonguetip (Anstis \& Loizos, 1967; Fitt, 1917; Grossman \& Hattis, 1967; Waterman, 1917) and with the tongue's capacities as an organ of exploration and manipulation. Because of its ability to extend beyond the margin of the lips, the tongue can be employed to evaluate the mechanical and thermal properties of objects much as the fingers do. Indeed, previous reports that lingual spatial acuity is superior to digital spatial acuity (e.g., Anstis \& Loizos, 1967) combine with the present results to provide persuasive evidence that the tonguetip may be the body region best endowed with the somatic senses. As a consequence, the simple act of licking an object is arguably one of the most effective exploratory behaviors in man's sensorimotor repertoire, enabling as it does the acquisition of extraordinary tactile and thermal information about the object while simultaneously sensing its chemical properties via taste and smell.

In summary, the heterogeneous responsiveness of labial and lingual skin to temperature change seems to reflect differences in both the innervation and thermal conductivity of those tissues. It follows that the comparatively better and more uniform responsiveness of the interior of the mouth to cooling probably is due to a more complete innervation of the oral regions by the cold sense than by the warm sense. This difference is conjectured to have resulted from a stronger adaptive pressure toward development of a sensitivity to cooling created by the high resting temperature of the mouth. The presumed differences in innervation of the warmth sense across oral regions (particularly in labial skin) offer opportunities for psychophysical confirmation of the contributions made by various kinds of thermal afferents to sensations of warmth, heat, and heat-pain. Perhaps future electrophysiological surveys of primate oral mucosa will reveal differences in the nature and/or the density of thermal innervation that are correlated with the perceptual differences reported here for humans.

\section{REFERENCES}

Anstis, S. M., \& Loizos, C. M. (1967). Cross-modal judgments of small holes. American Journal of Psychology, 80, 51-58.
Beitel, R. E., \& Dubner, R. (1976). Response of unmyelinated (C) polymodal nociceptors to thermal stimuli applied to the monkey's face. Journal of Neurophysiology, 39, 1160-1175.

Bessou, P., \& PERL, E. R. (1969). Response of cutaneous sensory units with unmyelinated fibers to noxious stimuli. Journal of Neurophysiology, 32, 1025-1043.

CABANAC, M. (1972). Thermoregulatory behavior. In J. Bligh \& R. E. Moore (Eds.), Essays on temperature regulation (pp. 19-36). New York: American Elsevier.

Dixon, A. D. (1962). The position, incidence and origin of sensory nerve terminations in the oral mucous membrane. Archives of Oral Biology, 1, 39-48.

DodT, E., \& ZotTERman, Y. (1952). Mode of action of warm recep tors. Acta Physiologia Scandinavica, 26, 345-357.

Dubner, R., Sumino, R., \& WoOD, W. I. (1975). A peripheral "cold" fiber population responsive to innocuous and noxious thermal stimuli applied to the monkey's face. Journal of Neurophysiology, 38, 1373-1389.

Frrt, A. B. (1917). The estimation of distances by sight and by touch: Some investigations into the evolution of the sense of touch. American Journal of Psychology, 28, 264-288.

Georgopoulos, A. P. (1976). Functional properties of primary afferent units probably related to pain mechanisms in primate glabrous skin. Journal of Neurophysiology, 39, 71-83.

Grossman, R. C., \& Hattis, B. F. (1967). Oral mucosal sensory innervation and sensory experience. In J. F. Bosma (Ed.), Oral sensation and perception (pp. 5-62). Springfield, IL: Thomas.

Halata, Z., \& Munger, B. L. (1983). The sensory innervation of primate facial skin. II. Vermilion border and mucosal lip. Brain Research Reviews, 5, 81-107.

HANDWERKER, H. O., \& NeHER, K.-D. (1976). Characteristics of Cfiber receptors in the cat's foot responding to stepwise increase of skin temperature to noxious levels. Pflïgers Archiv, 365, 221-229.

HENSEL, H. (1973). Cutaneous thermoreceptors. In A. Iggo (Ed.), Handbook of sensory physiology (Vol. 2, pp. 79-110). New York: SpringerVerlag.

Hensel, H., \& IGGo, A. (1971). Analysis of cutaneous warm and cold fibers in primates. Pflugers Archiv, 329, 1-8.

Hirsch, V. L., \& Schriever, H. (1929). Beitrag zur Sensibilitat der Zunge des Kehlkopfes und der hinteren Rachewand. Zeitschrifi fur Biologie, 89, 1-20.

IriuchiJima, J., \& ZotTERMAN, Y. (1960). The specificity of afferent cutaneous C fibers in mammals. Acta Physiologica Scandinavica, 49, 267-278.

JARRETT, A. (1980). The structure of the oral mucosa. In A. Jarrett (Ed.), The physiology and pathophysiology of the skin (Vol. 6, pp. 1871-1912). London: Academic Press.

Kenshalo, D. R., Decker, T., \& Hamlton, A. (1967). Comparisons of spatial summation on the forehead, forearm, and back produced by radiant and conducted heat. Journal of Comparative Physiological Psychology, 63, 510-515.

Kenshalo, D. R., \& Gallegos, E. S. (1967). Multiple temperature sensitive spots innervated by single nerve fibers. Science, 158 , 1064-1065.

KonieTZny, F., HENSEL, H. (1977). The dynamic response of warm units in human skin nerves. Pflügers Archiv, 370, 111-114.

LAMotTe, R. H., \& Thalhammer, J. G. (1982). Response properties of high-threshold cutaneous cold receptors in the primate. Brain Research, 244, 279-287.

LIPKIN, M., \& HARDY, J. D. (1954). Measurement of some thermal properties of human skin. Journal of Applied Physiology, 7, 212-217.

MARKS, L. E., \& GonZalez, R. R. (1974). Skin temperature modifies the pleasantness of thermal stimuli. Nature, 247, 473-475.

Marks, L. E., \& STEVens, J. C. (1973). Spatial summation of warmth: Influence of duration and configuration of the stimulus. American Journal of Psychology, 86, 251-267.

Marks, L. E., Stevens, J. C., \& TePper, S. J. (1976). Interaction of spatial and temporal summation in the warmth sense. Sensory Processes, 1, 87-98.

Molinari, H. H., Greenspan, J. D., \& Kenshalo, D. R. (1977). The effects of rate of change and adapting temperature on thermal sensitivity. Sensory Processes, 4, 354-362. 
Nagaki, J., Yamashita, S., \& Sato, M. (1964). Neural response of cat to taste stimuli of varying temperatures. Japanese Journal of Physiology, 14, 67-89.

NiELSEN, M. (1970). Heat production and body temperature during rest and work. In J. D. Hardy, A. P. Gagge, \& J. A. J. Stolwijk (Eds.), Physiological and behavioral temperature regulation (pp. 205-214). Springfield, IL: Thomas.

Poulos, D. A., \& Benjamin, R. M. (1968). Response of thalamic neurons to thermal stimulation of the tongue. Journal of Neurophysiology, 31, 28-43.

Poulos, D. A., \& LeNDE, R. A. 1970). Response of trigeminal ganglion neurons to thermal stimulation of oral-facial regions. I. Steadystate response. Journal of Neurophysiology, 33, 508-517.

Sandick, B. L., Engell, D. B., \& Maller, O. (1984). Perception of drinking water temperature and effects for humans after exercise. Physiology \& Behavior, 32, 851-855.

SATo, M. (1967). Gustatory response as a temperature-dependent process. In W. D. Neff (Ed.), Contributions to sensory physiology (Vol. 2, pp. 223-251). New York: Springer.

Schriever, V. H., \& Strughold, H. (1926). Uber die der Nasenund Rachenschleimhaut eigentumlichen Empfindungsqualitaten. Zeitschrift für Biologie, 84, 193-206.

Stevens, J. C. (1979). Variation of cold sensitivity over the body surface. Sensory Processes, 3, 317-326.

Stevens, J. C., \& Marks, L. E. (1971). Spatial summation and the dynamics of the warmth sensation. Perception \& Psychophysics, 9 , 319-398.

StEVENS, J. C., \& Marks, L. E. (1979). Spatial summation of cold. Physiology \& Behavior, 22, 541-547.

Stevens, J. C., Marks, L. E., \& Simonson, D. C. (1974). Regional sensitivity and spatial summation in the warmth sense. Physiology \& Behavior, 13, 825-836

Stevens, J. C., \& Stevens, S. S. (1963). The dynamics of subjective warmth and cold. In Temperature: Its measurement and control in science and industry (Vol. 3, pp. 239-243). New York: Reinhold.

Stoll, A. M., Chianta, M. A., \& Piergallini, J. R. (1982). Prediction of threshold pain skin temperature from thermal properties of materials in contact. Aviation, Space, and Environmental Medicine, 53, 1220-1223.

Strughold, H. (1925). Die topographie des Kaltesinnes in der Mundhohle. Zeitschrift fur Biologie, 83, 515-534.

Sumino, R., Dubner, R., \& STARKman, S. (1973). Responses of small myelinated "warm" fibers to noxious heat stimuli applied to the monkey's face. Brain Research, 62, 260-263.

Thalmann, R. (1965). Cross-modality matching in a study of abnormal loudness functions. Laryngoscope, 75, 1708-1726.

VENDRIK, A. J. H., \& Vos, J. J. (1957). A method for the measurement of the thermal conductivity of the human skin. Journal of Applied Physiology, 11, 211-215.

Waterman, C. N., JR. (1917). Hand-tongue space perception. Journal of Experimental Psychology, 2, 289-294.

Winslow, C.-E. A., \& Herrington, L. P. (1949). Temperature and human life. Princeton, NJ: Princeton University Press.

Yamada, M., Maruhashi, J., \& MiYake, N. (1952). The distribution of sensory spots on the oral mucous membrane. Japanese Journal of Physiology, 2, 328-332.
ZotTERman, Y. (1936). Specific action potentials in the lingual nerve of cat. Scandinavian Archives of Physiology, 75, 105-119.

\section{NOTES}

1. The term "responsiveness" is used throughout this paper to mean the perceptual excitability of skin to suprathreshold thermal stimulation. The term "sensitivity" is avoided because of its association with detection and discrimination, which were not measured in the present study.

2. Accurate measurement of skin temperature, while always difficult, was particularly troublesome in the present study because of the presence of saliva on the oral tissue. Surface skin temperature is typically monitored by simply placing a small thermocouple or thermistor against the skin, a procedure that usually provides a satisfactory measurement because the mass of the skin is large compared to that of the thermocouple and the ambient air. However, when the skin surface is hydrated, the temperature sensor may be heavily biased by the temperature of the liquid (saliva) in which it is bathed. Hence, when the mouth is closed, oral temperatures can reach as high as $37^{\circ} \mathrm{C}$ and remain stable; but when the mouth is open, exposure to ambient air produces immediate cooling of the saliva and skin owing to radiative and evaporative heat loss. Because of evaporative cooling in particular, the temperature signaled by the wet thermocouple falls continuously, making an accurate estimate of skin temperature at the time of stimulation problematic. A procedure was therefore developed to yield more stable temperature measurements by controlling the duration of mouth opening and by eliminating evaporative cooling at the moment of temperature measurement. This was achieved by first having the subject open his or her mouth to expose the locus under study for $5 \mathrm{sec}$ (the approximate time a subject normally sat with open mouth prior to stimulation), during which time the thermocouple was brought into contact with the region of skin to be measured. In addition, a $1-\mathrm{cm}^{2}$ piece of cork glued to a small handle was pressed lightly against the skin adjacent to the test site. At the end of $5 \mathrm{sec}$, the cork was moved laterally to cover the thermocouple and insulate it from further environmental cooling. (The cork surface was presumably near skin temperature because of its prior 5-sec skin contact, and was assumed, because of its extremely low conductivity, to be an insignificant thermal factor.) A temperature reading was then taken immediately (within $1 \mathrm{sec}$ ). Measurements made in this way were more reliable than without the cork insulator, although it is important to note that the continued presence of the cork for more than about $2 \mathrm{sec}$ began to produce local warming by trapping heat at the skin's surface. Because of the success of this method in the oral cavity, and for purposes of uniformity, all prestimulation skin temperatures were measured in this manner.

3. The occurrence of large $\Delta T$ s at the skin's surface do not necessarily reflect comparable $\Delta \mathrm{Ts}$ at subepithelial layers, as was pointed out in Experiment 1 . Large changes in superficial skin temperature can be either confined to the surface by an insulating epidermis or conducted to subepithelial structures in the absence of such insulation. Thus, hypotheses about deficits in thermal innervation should be made only when large $\Delta T$ s occur on skin that is assumed to be a good conductor of heat, as is the case with the hydrated epidermis of the mucosa.

(Manuscript received April 27, 1984; accepted for publication June 24, 1984.) 